\title{
Verbal fluency in dementia of frontal lobe type and dementia of Alzheimer type
}

\author{
Florence Pasquier, Florence Lebert, Laurence Grymonprez, Henri Petit
}

\begin{abstract}
This study compares semantic (category) and letter-initial verbal fluency performance in dementia of frontal lobe type, dementia of Alzheimer type, and control subjects matched for age, sex, and level of education. As well as demographic characteristics, patients were matched for severity of dementia as estimated by the mini mental scale (23.2 (SD 4.9)). All patients with dementia of frontal lobe type had a frontal hypoperfusion on single photon emission computed tomography whereas patients with dementia of Alzheimer type showed mainly posterior deficits. Patients had significantly lower verbal fluency than controls but those with dementia of frontal lobe type did not differ from those with dementia of Alzheimer type in the number of words generated, intrusions, or perserverations. Category fluency was more impaired than letter fluency in both dementias. No correlation between frontal index, frontal/parietal index, and fluency was found. Verbal fluency tests are sensitive tools for detecting dementia but do not seem useful in distinguishing between patients with dementia of Alzheimer type and those with dementia of frontal lobe type in early disease.
\end{abstract}

$(\Im$ Neurol Neurosurg Psychiatry 1995;58:81-84)

Keywords: Alzheimer's disease; verbal fluency; dementia of frontal lobe type

Verbal fluency tasks are useful cognitive measures for detecting dementia of Alzheimer type. ${ }^{1-3}$ Performance decrements in fluency tasks are correlated with activities of daily living and behaviour impairment measured by geriatric rating scales. ${ }^{4}$ Category fluency tasks have been found superior to letter fluency tasks in distinguishing patients with dementia of Alzheimer type from healthy elderly control subjects. ${ }^{3}$ This superiority may indicate deterioration of semantic knowledge even in early dementia of Alzheimer type. ${ }^{35}$ This test is, however, more sensitive than specific. Diminution of word fluency is supposed to be one feature of prefrontal dysfunction, ${ }^{67}$ especially of the left, dominant, hemisphere.$^{89}$ No particular region of the frontal lobe seems responsible for the verbal fluency deficit, but the volume of impaired tissue may be important. ${ }^{9}$ Subcortical lesions give rise to predominantly frontal dysfunction, due to the corticosubcortical loops linking the prefrontal cortex to the basal ganglia. ${ }^{10}$ Patients with Parkinson's disease, ${ }^{11}$ progressive supranuclear palsy, ${ }^{12}$ and Huntington's disease ${ }^{13}$ have specific difficulties in lexical fluency compared with patients with dementia of Alzheimer type matched for level of intellectual deterioration.

Dementia of frontal lobe type differs from dementia of Alzheimer type in several respects: the behavioural disorder (disinhibition, oral hyperactivity, restlessness, or social withdrawal) may precede the cognitive disorder; memory impairment, spatial disorientation, and an abnormal EEG are less common in the early stages. ${ }^{14}$ Early dementia of frontal lobe type is dominated by emotional and personality changes that may cause differential diagnostic problems with affective disorders. Patients with dementia of frontal lobe type show bilateral reduced regional cerebral blood flow in frontal, and especially prefrontal areas, by contrast with dementia of Alzheimer type, which shows a consistent reduction in the temporoparietal cortex. ${ }^{1516}$ It is important to distinguish dementia of frontal lobe type from Alzheimer's disease in terms not only of clinical diagnosis but also of treatment and research. ${ }^{14}$ The verbal fluency test seemed of potential value in this respect. ${ }^{17}$

The main purpose of this study was to compare category fluency and letter fluency performance in patients with dementia of frontal lobe type, patients with dementia of Alzheimer type matched for severity of dementia, and normal demographically matched elderly controls. The ancillary purpose was to look for a link between fluency task performance and the single photon emission computed tomography (SPECT) frontal uptake index.

\section{Patients and methods PATIENTS}

Outpatients with cognitive difficulties were recruited from the University Memory Disorders Unit. All fulfilled the diagnostic and statistical manual of mental disorders, third edition, revised 18 criteria for "primary degenerative dementia" after evaluation by one senior staff neurologist and one senior staff psychogeriatrician. Dementia of frontal lobe type was diagnosed clinically, from the history, neuropsychological testing, and indications provided by Gustafson, ${ }^{19}$ Neary et $a l,{ }^{20}$ and Cole. ${ }^{17}$

Patients with dementia of frontal lobe type 
had a history of behavioural disturbance predating dementia, with early personality change, loss of social skills, disinhibition, and apathy. The family considered memory impairment of secondary importance compared with the behavioural disorder. Affect was flat or bland. Two had hypochondriacal delusions. None had visuospatial impairment and especially no spatial disorientation. The EEG was normal in all cases.

Dementia of Alzheimer type was diagnosed according to National Institute of Neurological and Communicative Disorders and Stroke and Alzheimer's Disease and Related Disorder Association criteria. ${ }^{21}$ Ten patients with probable Alzheimer's disease were selected from the memory disorders unit data file to be matched with the first 10 consecutive patients with dementia of frontal lobe type able to achieve the verbal fluency task. The selection criteria were sex, level of education (six to seven years of schooling, $n=6$, 11-15 years of schooling, $n=4)$, age $( \pm 5$ years), typical Alzheimer syndrome (insidious onset, progressive memory loss, language and visuospatial disorders, often accompanied by minor behavioural disturbance such as suspiciousness) and mini mental state examination $^{22}$ scores ( \pm 2 points). Patients with severe cognitive impairment were excluded, as they could not perform the task and as both frontal lobe dysfunction and pronounced behavioural disturbance have been reported in advanced Alzheimer's disease. ${ }^{1723}{ }^{24}$ None received psychotropic medication in the month before the study. Patients had no previous neurological or psychiatric history. Clinical examination and laboratory investigations were normal. The Ischaemic score ${ }^{25}$ was $<4$ and no abnormality other than atrophy was found on CT or MRI.

Patients were assessed with a comprehensive neuropsychological test battery including the Mattis dementia rating scale, ${ }^{26}$ digit span, logical memory subtest (Wechsler memory scale), selective reminding test (Bushke), ${ }^{27}$ delayed visual recognition, ${ }^{28}$ assessment of aphasia, agnosia, gestual, and constructive apraxia, and semistructured interview with the patient and family conducted by a psychogeriatrician. The memory deficit, and especially Grober and Buschke enhanced cued recall ${ }^{27}$ was compatible with an organic mental disorder in all cases.

A SPECT study with $99 \mathrm{~m}$ Tc-HM-PAO (Tomomatic 564, Medimatic, Copenhagen) was performed on 14 patients (seven with dementia of Alzheimer type and seven with

Demographic data (mean (SD)) of patients with dementia of frontal lobe type (DFT), dementia of Alzheimer type (DAT), and control subjects (CS)

\begin{tabular}{|c|c|c|c|c|c|c|}
\hline & $\begin{array}{l}D F T \\
(n=10)\end{array}$ & $\begin{array}{l}D A T \\
(n=10)\end{array}$ & $\begin{array}{l}C S \\
(n=10)\end{array}$ & $d f$ & F Value & p Value \\
\hline $\begin{array}{l}\text { Age (y) } \\
M / F\end{array}$ & $\underset{5 / 5}{65 \cdot 5}(10 \cdot 4)$ & $\begin{array}{l}68 \cdot 2(8 \cdot 9) \\
5 / 5\end{array}$ & $\begin{array}{c}66 \cdot 8(8 \cdot 1) \\
5 / 5\end{array}$ & 2,27 & $0 \cdot 22$ & $0 \cdot 81$ \\
\hline Education (y) & $8.9(3.5)$ & $8 \cdot 5(2 \cdot 5)$ & $9 \cdot 1(3 \cdot 7)$ & 2,27 & 0.09 & 0.92 \\
\hline Age at onset (y) & $62 \cdot 0(9 \cdot 1)$ & $65 \cdot 3(8 \cdot 5)$ & - & 1,18 & $0 \cdot 70$ & 0.41 \\
\hline Duration $(y)$ & $3.4(2 \cdot 8)$ & $2 \cdot 3(1 \cdot 3)$ & - & 1,18 & 1.26 & $0 \cdot 28$ \\
\hline MMSE score & $23.9(4.4)$ & $23 \cdot 1(5 \cdot 2)$ & - & 1,18 & 0.14 & 0.72 \\
\hline Mattis DRS & $117 \cdot 4(18 \cdot 9)$ & $118.5(12.4)$ & - & 1,18 & 0.02 & $0 \cdot 87$ \\
\hline
\end{tabular}

dementia of frontal lobe type). Cerebral uptake indices were calculated bilaterally with the cerebellum as reference in frontal and parietal cortical regions. All patients with dementia of frontal lobe type showed the characteristic frontal hypoperfusion pattern whereas patients with dementia of Alzheimer type showed mainly posterior metabolic deficits. ${ }^{14} 23$ 29-31

Ten voluntary control subjects were matched for sex, level of education, and age. Their mini mental state examination score was $\geqslant 29$ and they had no neurological or psychiatric history. They did not undergo SPECT.

All patients and controls were native French speakers.

\section{PROCEDURE}

Subjects were asked to provide as many animal words as they could for the category fluency task (excluding proper nouns and variants) and as many words beginning with $P$ as they could for the letter fluency task, in two minutes. The verbal fluency tasks were given by the same speech therapist, blinded to the final diagnosis of dementia (dementia of Alzheimer type or dementia of frontal lobe type).

The scores analysed (by analysis of variance (ANOVA)), were the total number of correct answers for each fluency task, the number of intrusions (non-animal words in the category task, words not beginning with $\mathrm{P}$ in the fluency task), and the number of perseverations for each fluency task.

\section{Results}

The table gives the demographic characteristics.

\section{VERBAL FLUENCY (FIGURE)}

Repeated measures ANOVA showed a significant group effect $(F(2,27)=3 \cdot 39, p=0 \cdot 04)$. Controls produced more words than dementia of Alzheimer type + dementia of frontal lobe type $(F(1,27)=6 \cdot 74, p=0.01)$. Type of fluency task was also significant (category $v$ letter $P, F(1,27)=97.43, p<0.0001)$ : both controls and patients generated more animal

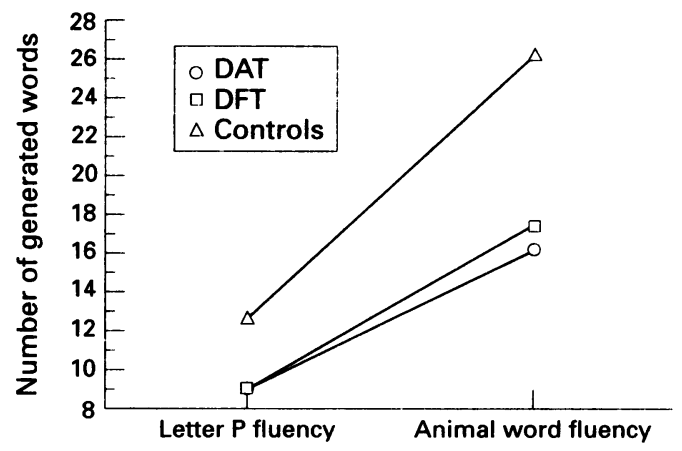

Verbal fluency (mean score) in patients with dementia of frontal lobe type (DFT), dementia of Alzheimer type $(D A T)$, and controls. 
names than words beginning with $P$. There was a significant interaction between group (controls $v$ dementia of Alzheimer type $v$ dementia of frontal lobe type) and type of fluency $(F(2,27)=4 \cdot 05, p=0 \cdot 02)$. The difference between controls and patients was larger for animal than for letter fluency (interaction between type of fluency and the contrast $(F(1,27)=7 \cdot 85, p=0 \cdot 009))$. There were no significant differences between dementia of Alzheimer type and dementia of frontal lobe type in the number of words generated $(25.5$ $(\mathrm{SD} 10.7)$ v $26.7(14.5), \mathrm{F}(1,18)=0.04, \mathrm{p}=$ $0,83)$, intrusions $(0.10(0.3) v 0.20(0.6)$, $\mathrm{F}(1,18)=0.2, \mathrm{p}=0.66)$, or perseverations $(1.2(1.9)$ v $1.3(1.8), \mathrm{F}(1,18)=0.01, \mathrm{p}=$ $0.90)$. There was no interaction between type of dementia (dementia of Alzheimer type $v$ dementia of frontal lobe type) and type of fluency $(F(1,18)=0 \cdot 21, p=0 \cdot 65)$.

\section{SPECT PATTERN}

Frontal index values were lower in patients with dementia of frontal lobe type than in those with dementia of Alzheimer type (78.52 (5.08) $v$ 84.94 (5.07), $\mathrm{F}(1,12)=5.59, \mathrm{p}<$ $0.04)$. There was no significant asymmetry. Parietal values did not differ between the dementia of frontal lobe type and dementia of Alzheimer type groups $(85.64(2.81) v 83.57$ $(6 \cdot 23), F(1,12)=0.64, p=0.44)$. The mean frontal:parietal ratio was $0.92(0.07)$ in dementia of frontal lobe type and $1.02(0 \cdot 10)$ in dementia of Alzheimer type $(F(1,12)=$ $4 \cdot 42, \mathrm{p}=0 \cdot 05$ ).

No correlation was found between frontal index, frontal/parietal index, and fluency.

\section{Discussion}

These results confirm the sensitivity of verbal fluency tasks in early or mild dementia. ${ }^{32}$ They agree with most previous findings ${ }^{33-35}$ in showing that category fluency is more impaired than letter fluency in dementia of Alzheimer type. They disagree with Rosen ${ }^{32}$ who found greater impairment in letter than in semantic category fluency in early dementia of Alzheimer type. But our data fail to show greater impairment in patients with dementia of frontal lobe type than in patients with dementia of Alzheimer type matched for demographical characteristics and severity of dementia presenting with the typical parietal syndrome of dementia of Alzheimer type, based on clinical and SPECT features. Even at this early stage, SPECT showed lower frontal indices in dementia of frontal lobe type, in agreement with the clinical presentation and literature data. There was no interaction between type of fluency and type of dementia. In particular, the greater impairment in category than letter fluency was not significantly higher in dementia of Alzheimer type than in dementia of frontal lobe type, whereas frontally impaired patients were expected to perform poorly in any fluency task. This result emphasises the lack of specificity suspected by Monsch et al. ${ }^{3}$ Semantic impairment seems non-specific as semantic memory was not specifically impaired in dementia of Alzheimer type, as opposed to multi-infarct dementia of comparable severity. ${ }^{36}$ By contrast, category fluency correlates with the degree of dementia in both diseases. ${ }^{36}$ Furthermore, mildly demented Huntington's disease shows the same pattern of "disruption in the structure of semantic knowledge" as dementia of Alzheimer type matched for severity of dementia in the supermarket fluency task on the Mattis dementia rating scale. ${ }^{37}$ The difference between category and letter fluency performance is thought to be more pronounced in early dementia of Alzheimer type where impairment of language tasks may be due more to a deterioration in semantic knowledge than to psychomotor slowing. ${ }^{3}$

Impaired verbal fluency is a classic feature of frontal lobe dysfunction. Attempts to localise function within the prefrontal cortex in humans have not yet produced consistent results. ${ }^{38}$ Verbal fluency deficit has been consistently reported as impaired in both cortical and subcortical dementia, but performance in specific fluency tests follows a less consistent pattern, not only between studies but also within studies depending on the letter or category target. ${ }^{10111338-41}$ Diesfeld $^{42}$ showed that low verbal fluency in dementia of Alzheimer type was probably not due to a loss of words and their meanings, but rather to a reduced accessibility of words. Successful retrieval depends on retrieval strategies as well as on the storage characteristics of the information to be retrieved. In dementia of Alzheimer type, loss of the specific features and associations of words ${ }^{53}$ reduces the availability of attributes necessary to arouse a concept-for example, of a specific kind of fruit or animal. The reduction in the availability of the set of attributes that determine word meanings leads to inadequate activation of the concept, which, in turn, may prevent retrieval of its name. ${ }^{42}$ In dementia of frontal lobe type, low category fluency performance could be due to impairment of the strategies needed to generate the maximum of items of a category in a limited time. Retrieval of words from a category is likely to depend on breaking the category down into subcategories and systematically searching each subcategory. A systematic strategy also reduces the resampling tendency (reretrieval of previously recalled items) that is almost inevitable during retrieval, even in normal subjects. ${ }^{44} \mathrm{~A}$ systematic search strategy necessarily implies a working memory that "temporarily holds the rules of the search procedure and keeps a tally of recalled category exemplars". ${ }^{4}$ Reduced short term memory capacity in patients with dementia could partially explain impaired fluency performance.

Because reduced verbal fluency performance may be due to a dysfunction of one or several complex processes, verbal fluency tests are sensitive tools for detecting dementia but do not seem useful for distinguishing between dementia of Alzheimer type and dementia of frontal lobe type in early disease. 
This work was supported by the Direction de la Recherche et des études Doctorales (DRED) du Ministère de l'Enseignement Supérieur et de la Recherche (Grant ER 153) and the Commission Mixte CHRU-Faculté de Médecine de Lille (Grant 9306 ).

We are grateful to Alain Duhamel (Centre d'Etudes et de Recherche en Informatique Médicale, Lille) who revised the statistical analysis.

1 Hart S, Smith CM, Swash M. Word fluency in patients with early dementia of Alzheimer type. Br f Clin Psychol 1988;28:115-24.

2 Girling DM, Berrios GE. Extrapyramidal signs, primitive reflexes and frontal lobe function in senile dementia of reflexes and frontal lobe function in senile dementimer type. Br f Psychiatry 1990;157:888-93.

Alzheimer type. Br f Psychiatry 1990;157:888-93.
3 Monsch AU, Bondi MW, Butters N, Salmon DP, Katzman R, Thal LJ. Comparisons of verbal fluency Katzman R, Thal LJ. Comparisons of verbal fluency tasks in the detection of dementi

4 Diesfeldt HFA. Verbal fluency tests and their significance for psychogeriatric practice. Tijdschr Gerontol Geriatr 1983;14:49-59.

5 Martin A, Fedio P. Word production and comprehension in Alzheimer's disease: the breakdown of semantic knowledge. Brain Lang 1983;19:124-41.

6 Pendleton MG, Heaton RK, Lehmen RWA, Hulihan D. Diagnostic utility of the Thurstone word fluency test in neuropsychiatric evaluations. F Clin Neuropsychol 1982;4: 307-17.

7 Crockett D, Bilsker D, Hurwitz T, Kozak J. Clinical utility of three measures of frontal lobe dysfunction in neu-
ropsychiatric samples. Int $\mathcal{F}$ Neurosci 1986;30:241-8.

8 Milner B. Interhemispheric differences in the localization of psychological processes in man. Br Med Bull 1971; of psycho:

9 Hécaen $H$, Ruel $H$. Sièges lésionnels intrafrontaux et déficit au test de "fluence verbale". Rev Neurol 1981, 137:277-84.

10 Brown RG, Marsden CD. Subcortical dementia: The neuropsychological evidence. Neuroscience 1988;25 363-87.

11 Huber SJ, Shuttleworth EC. Neuropsychological assessment of subcortical dementia. In: Cummings JL, ed. Subcortical dementia. New York: Oxford University Press; 1990:71-86.

12 Pillon B, Dubois B, Lhermitte F, Agid Y. Heterogeneity of cognitive impairment in progressive supranuclear palsy, Parkinson's disease, and Alzheimer's disease. Neurology 1986;6:1179-85.

13 Pillon B, Dubois B, Agid Y. Severity and specificity of $\operatorname{cog}$ nitive impairment in Alzheimer's, Huntington's, and nitive impairment in Alzheimer's, Huntington's, and Parkinson's diseases and prog

14 Gustafson L, Brun A, Risberg J. Frontal lobe dementia of non-Alzheimer type. In: Wurtman RJ, Corkin S, Growdon JH, Ritter-Walker E, eds. Alzheimer's disease, advances in Neurology Vol 51, New York: Raven Press, 1990:65-71.

15 Duara R, Grady C, Haxby J, et al. Positron emission tomography in Alzheimer's disease. Neurology 1986;36:879-87.

16 Burns A, Philpot MP, Costa DC, Ell PJ, Levy R. The investigation of Alzheimer's disease with single photon emission tomography. I Neurol Neurosurg Psychiatry 1989;52:248-53.

17 Cole AJ. A survey of frontal lobe dementia in a psychogeriatric day unit population. International fournal of Geriatric Psychiatry 1992; 7:731-8.

18 American Psychiatric Association, Committee on Nomenclature and Statistics. Diagnostic and statistical Nomenclature and Statistics. Diagnostic and statistical manual of mental disorders. 3rd ed revised.

19 Gustafson L. Frontal lobe degeneration of non-Alzheimer type. II. Clinical picture and differential diagnosis Archives of Gerontology and Geriatrics 1987;6:209-23.

20 Neary D, Snowden JS, Northen B, Goulding P. Dementia of frontal lobe type. $\mathcal{f}$ Neurol Neurosurg Psychiatry 1988;51:353-61

21 McKhann G, Drachman D, Folstein M, Katzman R, Price D, Stadlan EM. Clinical diagnosis of Alzheimer's dis- ease: report of the NINCDS-ADRDA work group under the auspices of Department of Health and Human Services Task Force on Alzheimer's disease. Neurology

22 Folstein MF, Folstein SE, McHugh PR. "Mini mental state": a practical method for grading the cognitive state of patients for the clinician. I Psychiatr Res 1975; 12:189-98.

23 Neary D, Snowden JS, Shields RA, et al. Single photon emission tomography using $99 \mathrm{mTc}-\mathrm{HM}-\mathrm{PAO}$ in the investigation of dementia. $\mathcal{F}$ Neurol Neurosurg Psychiatry 1987;50:1101-9.

24 Montaldi D, Brooks DN, McColl JH, et al. Measurements of regional cerebral blood flow and cognitive performance in Alzheimer's disease. $\mathcal{f}$ Neurol Neurosurg Psychiatry 1990;53:33-8.

25 Hachinski VC, Iliff LD, Zilka E, et al. Cerebral blood flow in dementia. Arch Neurol 1975;32:632-7.

26 Mattis S. Mental status examination for organic mental syndrome in the elderly patients. In: Bellak L, Karasu syndrome in the elderly patients. In: Bellak L, Karasu TB, eds. Geriatric psychiatry: A hand book for psychiatrists and primary care physician

27 Grober E, Buschke H, Crystal MD, Bang MA, Dresner R. Screening for dementia by memory testing. Neurology 1988;38:900-3

28 Signoret JL. Batterie d'Efficience Mnésique. Paris: Elsevier, 1991.

29 Risberg J. Frontal lobe degeneration of non-Alzheimer type. III Regional cerebral blood flow. Archives of Gerontology and Geriatrics 1987;6:225-33.

30 Jagust WJ, Reed BR, Seab JP, Kramer JH, Budinger TF. Clinical-physiologic correlates of Alzheimer's disease and frontal lobe dementia. Am $\mathcal{F}$ Physiol Imaging 1989; 4:89-96.

31 Miller BL, Cummings JL, Villanueva-Meyer J, Boone $\mathrm{K}$ Mehringer CM, Lesser IM, Mena I. Frontal lobe Mehringer CM, Lesser IM, Mena I. Frontal lobe degeneration: Clinical neuropsychological,

32 Rosen WG. Verbal fluency in aging and dementia. $f \mathrm{Clin}$ Neuropsychol 1980;2:135-46.

33 Weingartner H, Kaye W, Smallberg SA, Ebert MH, Gillin JC, Sitram N. Memory failure in progressive idiopathic dementia. f Abnorm Psychol 1981;90:187-96.

34 Butters N, Granholm E, Salmon DP, Grant I, Wolfe J. Episodic and semantic memory: a comparison of amnesic and demented patients. $\mathcal{F}$ Clin Exp Neuropsychol 1987;9:479-97.

35 Shuttelworth EC, Huber SJ. The naming disorders of dementia of Alpheimer type Brain Lang 1988:34:22-34.

36 Fisher P, Gatterer G, Martere A, Danielczyk W. Nonspecificity of semantic impairment in dementia of Alzheimer's type. Arch Neurol 1988;45:1341-3.

37 Tröster AI, Salmon DP, McCullough D, Butters N. A comparison of the category fluency deficits associated with Alzheimer's and Huntington's disease. Brain Lang 1989;37:500-13.

38 Brown RG, Marsden CD. Cognitive function in Parkinson's disease: from description to theory. Trends Neurosci 1990;13:21-9.

39 Growdon JH, Corkin S, Rosen TJ. Distinctive aspects of cognitive dysfunction in Parkinson's disease. In: Streifle $\mathrm{MB}$, Korczyn AD, Melamed E, Youdim $\mathrm{MBH}$, eds. Advances in Neurology, Vol 53, Parkinson's disease: anatomy, pathology and therapy. New York: Raven Press, 1990:365-76.

40 Gurd JM, Ward CD, Hodges J. Parkinson's disease and the frontal hypothesis: task alternation in verbal fluency. In: Streifler MB, Korczyn AD, Melamed E, Youdim MBH, eds. Advances in Neurology, Vol 53, Parkinson's disease: anatomy, pathology and therapy. New York: disease: anatomy, pathology

41 Cooper JA, Sagar HJ, Jordan N, Harvey NS, Sullivan EV. Cognitive impairment in early, untreated Parkinson's Cognitive impairment in early, untreated Parkinson's 1991;114:2095-122.

42 Diesfeldt HFA. Verbal fluency in senile dementia: an analysis of search and knowledge. Archives of Gerontology and Geriatrics 1985;4:231-9.

43 Warrington EK. The selective impairment of semantic memory. Qf Exp Psychol 1975;27:635-57.

44 Raaijmakers JWG, Shiffrin RM. Search of associative memory. Psychol Rev 1981;88:93-134. 